\title{
Prediction of Hardness for Partially Quenched Boron Steel Using Quench Factor Analysis
}

\author{
J. Y. Choi ${ }^{1, *}$, J. H. Kim ${ }^{1}$, D. H. Ko ${ }^{1}$, P. K. Seo ${ }^{2}$, D. C. Ko ${ }^{3}$, B. M. Kim ${ }^{4}$ \\ ${ }^{1}$ Precision Manufacturing System Division, Pusan Nat'l University, South Korea \\ ${ }^{2}$ Department of Production, Shinyoung Co. Ltd., South Korea \\ ${ }^{3}$ Industrial Liaison Innovation Center, Pusan Nat'l University, South Korea \\ ${ }^{4}$ School of Mechanical Engineering, Pusan Nat'l University, South Korea
}

Copyright ( $\subset 2015$ by authors, all rights reserved. Authors agree that this article remains permanently open access under the terms of the Creative Commons Attribution License 4.0 International License

\begin{abstract}
The mechanical properties of hot stamped boron steel have been generally predicted by many empirical models based on the Kirkaldy's equation. Although predicting previous models are well-developed for prediction of mechanical properties, use of those models is still limitary in case of partial quenching process for tailored properties of component. Therefore, this study predicted the mechanical property of partially quenched boron steel by heated tools using the FE-simulation coupled with quench factor analysis (QFA). The dilatometry test of boron steel is performed at various ranges of cooling rates from 0.5 to $70^{\circ} \mathrm{C} / \mathrm{s}$ of which results are used to determine the material constants $\left(K_{1} \sim K_{5}\right)$ of QFA and the time-temperature-property (TTP) diagram of boron steel. And then, FE-simulation of partial quenching is carried out to obtain the cooling curves according to heating temperatures of tool. The extracted results from FE-simulation are combined with the QFA to calculate the hardness distribution of partially quenched parts. Finally, experiment of partial quenching is performed to verify the predicted results and to examine the effect of tool temperatures on the hardness of formed part. The predicted hardnesses of U-channel parts are in good agreement with the measured ones within a maximum error of $7.4 \%$.
\end{abstract}

Keywords Quenching Factor Analysis, Time-temperature-property Diagram, Hardness, Partial Quenching, Tool Tempering, Dilatometry Test

\section{Introduction}

In the automotive industry, hot stamped components are widely used in order to reduce the weight of vehicle and improve the fuel efficiency. During the conventional hot stamping, austenitized blank are formed and subsequently quenched by water-cooled tools with cooling rate above $30^{\circ} \mathrm{C} / \mathrm{s}$ which results in transformation of austenite into martensitic microstructure with ultra-high-strength-steel (UHSS) of 1.5GPa [1]. However, conventionally hot stamped components exhibit a low ductility and crashworthiness, so they are not recommended to automotive parts relevant to high crash performance such as the B-pillars [2].

Therefore, many researchers are recently focusing on the modification of conventional hot stamping called as partial quenching (or tailored tempering) to manufacture the component with tailored mechanical properties [2-4]. Partial quenching process is generally classified by following methods: tailored blank tempering; tailored tool tempering; post tempering of hot stamped parts [5]. Especially, tailored tool tempering is most widely used process in the automotive industry because it provides tailored property to component with a lower unit cost of production. In the tailored tool tempering of partial quenching, ductility of component is obtained by heating of tool in which certain regions locally experience a lower cooling rate below $30^{\circ} \mathrm{C} / \mathrm{s}$. Hence, heating temperature of tool is main factor to obtain the desired mechanical property such as hardness and tensile strength. Therefore, prediction technique of mechanical properties is vitally required for partial quenching process.

Mechanical property for tool tempering of boron steel has been predicted by many researchers using the commercial or developed FE codes. George et al. [3] developed a numerical model of the partial quenching using LS-DYNA ${ }^{\mathrm{TM}}$ to predict the Vickers hardness of formed B-pillar. Ertürk et al. [6] implemented a fully coupled thermo-mechanical -metallurgi cal model using the FE code AutoForm ThermoSolver ${ }^{\mathrm{TM}}$. Tang et al. [2] developed and implemented a numerical model using commercial FE code FORGE ${ }^{\mathrm{TM}}$ with more accuracy for prediction of mechanical property in partial quenching process. Aforementioned models are the kinetics of phase transformation based on the Kirkaldy's equation [7] which can predict both hardness and phase fraction such as martensite, bainite, ferrite and pearlite. However, finally predicted hardness by Kirkaldy's equation is calculated from each phase of fraction, microhardness and cooling rate which 
is usually used as average cooling rate at certain temperature range [8]. Hence, in case of partial quenching, use of average cooling rate may be at risk for over- or under-calculation of mechanical property because blank temperature at certain region subsequent forming is kept by the heated tools.

Therefore, partially quenched property (Hardness) in this study was predicted by the quench factor analysis (QFA) of which basic theory was referred to as the Johnson-Mehl-Avrami-Kolmogorov (JMAK) equation. Since predicted hardness by QFA is calculated from the cooling history of part, this model is suitable to predict the hardness of partial quenching with more accurate value. Hence, this study aims to predict the tailored property of tool tempering among partial quenching methods according to heating temperatures of tool. First of all, dilatometry test of austenitized boron steels was performed to obtain the material constants $\left(K_{1} \sim K_{5}\right)$ of QFA at various range of cooling rates from 0.5 to $70^{\circ} \mathrm{C} / \mathrm{s}$ using the dilatometer forced to air cooling system. And then, hardness distributions of partially quenched parts were predicted by FE-simulation coupled with QFA which was developed in this study using the commercial FE code JSTAMP/NV 2.2.5. Finally, experiment of partial quenching was performed according to heating temperatures of tool for a laboratory scale U-channel part of laboratory scale. The temperature histories and hardnesses at predefined locations in the part were compared with predicted ones these results showed that the predicting technique of this study was very effective for prediction of partially quenched hardness by heated tool.

\section{Determination of Material Constants for Boron Steel}

Quench factor analysis (QFA). QFA provides a single number $Q$ that interrelates the cooling curve in the part and the transformation kinetics of alloy being quenched. The basic theory for QFA is referred to as the Johnson-Mehl-Avrami-Kolmogorov (JMAK) equation as following Eq. (1) [9].

$$
X=1-\exp (-k t)^{n}
$$

where $X$ is the transformed volume fraction, $n$ is the Avrami exponent (constant), and $k$ is a temperature dependent constant. Transformation and hardening characteristic of alloy were described by the time-temperature-property (TTP) diagram which was developed by Evancho and Staley [10] as mathematical expression ( $C_{\mathrm{t}}$ function) with the following equation such as

$$
C_{\mathrm{t}}=-K_{1} \cdot K_{2} \cdot \exp \left(\frac{K_{3} \cdot K_{4}{ }^{2}}{R \cdot T\left(K_{4}-T\right)^{2}}\right) \cdot \exp \left(\frac{K_{5}}{R \cdot T}\right)
$$

where $C_{\mathrm{t}}$ is critical time required to transform a constant amount of ferrite, pearlite or bainite, typically $0.5 \%$, of which locus is the start of transformation in the TTP diagram. $K_{1}$ is a constant which equals the natural logarithm of the volume fraction for untransformed austenite during quenching (typically $99.5 \%$; $\ln (0.995)=-0.00501), K_{2}$ is a constant related to the reciprocal of the number of nucleation sites, $K_{3}$ is a constant related to the energy required to form a nucleus, $K_{4}$ is a constant related to the carbon solvus temperature $\left(\mathrm{A}_{\mathrm{c} 3}\right)$ and $K_{5}$ is a constant related to the activation energy for diffusion. $R$ is $8.3143 \mathrm{~J} / \mathrm{kmol}$ as gas constant and $T$ is the average temperature $(\mathrm{K})$ between successive time steps.

In order to use the QFA, the incremental quench factor $(q)$ is firstly calculated for each time interval in the cooling curve and it means that the ratio of holding time of steel at a particular temperature to the time required for $0.5 \%$ transformation at that temperature. And then, the values of incremental quenching factor are summed over the transformation range between $M_{s}$ and $A_{c 3}$ temperature to produce cumulative quench factor $(Q)$, according to Eq. (3).

$$
Q=\sum q=\sum_{T=M_{s}}^{T=A_{c} 3} \frac{\Delta t}{C_{t}}
$$

where $q$ is the incremental quench factor, $\Delta t$ is the time step for data acquisition in cooling curve. $M_{\mathrm{s}}$ and $A_{\mathrm{c} 3}$ are martensite start and solvus temperatures, respectively. Quench factor can be related to certain as-quenched mechanical properties of steel such as hardness and strength according to Eq. (4) in which low value of $Q$ means a good mechanical properties with fast quenching rate. In contrast, high value of $Q$ indicates a poor mechanical properties with slow quenching rate.

$$
P_{p}=P_{\text {min }}+\left(P_{\text {max }}+P_{\text {min }}\right) \cdot \exp \left(K_{1} \cdot Q\right)
$$

where $P_{\mathrm{p}}$ is the predicted property, $P_{\min }$ and $P_{\max }$ are minimum and maximum property of quenched part, respectively. The minimum and maximum properties in this study are used as furnace cooled and water quenched hardness of boron steel, respectively.

Dilatometry test. In order to determine the material constants in the Eq. (1), dilatometry test of boron steel was performed at different cooling rates ranging from 0.5 to $70^{\circ} \mathrm{C} / \mathrm{s}$. The test was conducted by the quenching dilatometer forced to air cooling system and the specimens were austenitized at $900^{\circ} \mathrm{C}$ under the soaking time of $5 \mathrm{~min}$. Also, the chemical composition of boron steel employed in this study was summarized in Table 1.

Fig. 1(a) shows the hardness data of boron steel according to different cooling curves at austenitizing condition of $900^{\circ} \mathrm{C}$ for $5 \mathrm{~min}$. The results indicated the range of hardness from $157 \mathrm{Hv}$ to $457 \mathrm{Hv}$ and the increase in cooling rate leads to the high hardness. Moreover, hardnesses at high cooling rate above $30^{\circ} \mathrm{C} / \mathrm{s}$ are almost similar with values of 452 to $457 \mathrm{Hv}$. Hardness data according to cooling curves were used to determine the material constants of QFA.

In this study, material constants of $K_{1}$ to $K_{5}$ are determined using the FPS (Flexible polyhedron search) [11] based on hardnesses and cooling curves by the dilatometry test. FPS of 
this study is programmed using the MATLAB R2010a and it is iteratively run until mean squared error is minimized within error of $10 \%$. Values of $K_{1}$ to $K_{5}$ are summarized in Table 2. $K_{1}$ is fixed as typical value of $-0.00501(\ln (0.995))$ and value of $K_{5}$ is cited from the literature as $40,000 \mathrm{~J} / \mathrm{mol}$ [12]. Also, $P_{\max }$ value of auestenitizing temperature of 900 ${ }^{\circ} \mathrm{C}$ are used as $509 \mathrm{Hv}$ of water quenched specimen, whereas $P_{\min }$ values are employed as $149 \mathrm{Hv}$ of air cooled specimens at $0.5^{\circ} \mathrm{C} / \mathrm{s}$, respectively.

Table 1. Chemical composition of boron steel used in this study.

\begin{tabular}{c|c|c|c|c|c|c|c}
\hline Composition & $\mathrm{C}$ & $\mathrm{Si}$ & $\mathrm{Mn}$ & $\mathrm{Cr}$ & $\mathrm{Ti}$ & $\mathrm{Al}$ & $\mathrm{B}$ \\
\hline Wt.\% & 0.220 & 0.271 & 1.180 & 0.148 & 0.028 & 0.057 & 0.003 \\
\hline
\end{tabular}

Table 2. Material constants of boron steel for QFA at austenitizing condition of $900^{\circ} \mathrm{C}$ for $5 \mathrm{~min}$.

\begin{tabular}{c|c|c|c|c|c|c}
\hline$K_{1}$ & $K_{2}$ & $\begin{array}{c}K_{3} \\
(\mathrm{~J} / \mathrm{mol})\end{array}$ & $\begin{array}{c}K_{4} \\
(\mathrm{~K})\end{array}$ & $\begin{array}{c}K_{5} \\
(\mathrm{~J} / \mathrm{mol})\end{array}$ & $\begin{array}{c}P_{\max } \\
(\mathrm{Hv})\end{array}$ & $\begin{array}{c}P_{\min } \\
(\mathrm{Hv})\end{array}$ \\
\hline-0.00501 & 0.0494 & 331.32 & $\begin{array}{c}117 \\
3\end{array}$ & $\begin{array}{c}40,000 \\
{[15]}\end{array}$ & 509 & 149 \\
\hline
\end{tabular}

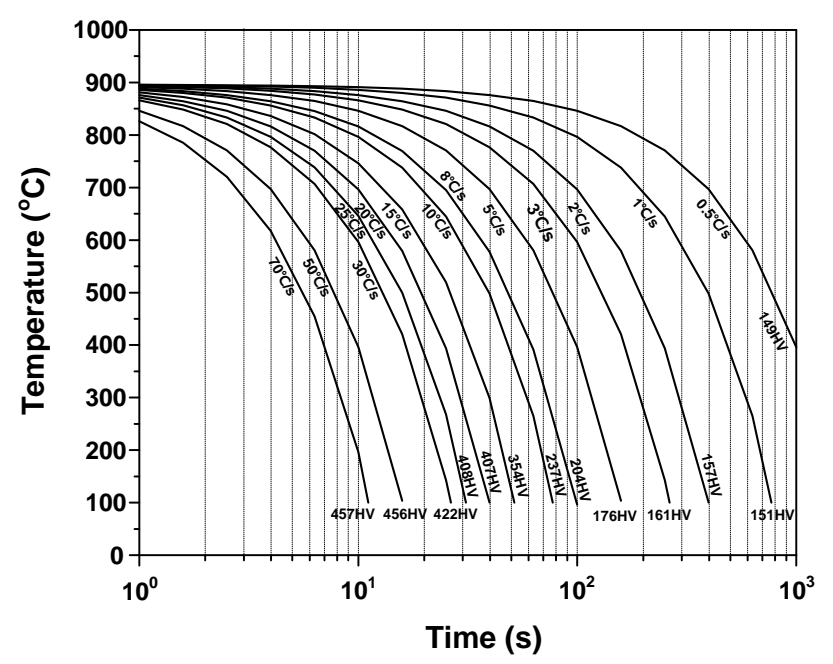

(a) Hardness and cooling curves

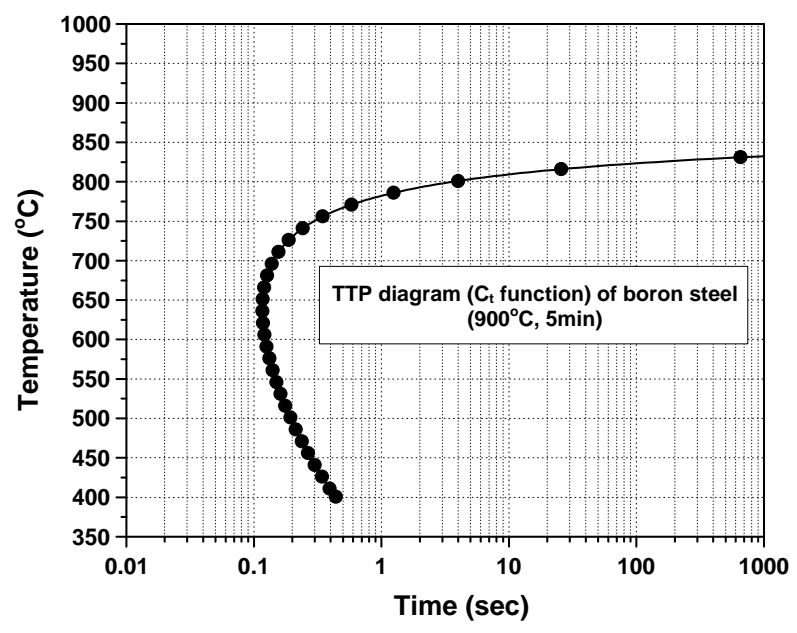

(b) TTP diagram ( $C_{t}$ function)

Figure 1. Hardnesses with different cooling curves (rates) and TTP diagram of boron steel at austenitizing condition of $900^{\circ} \mathrm{C}$ for $5 \mathrm{~min}$.
By substitution of material constants into $C_{\mathrm{t}}$ function of Eq. (1), TTP diagram of boron steel for austenitizing temperature of $900^{\circ} \mathrm{C}$ can be plotted as shown in Fig. 1(b). The TTP diagrams of boron steel were " $\mathrm{C}$ " shaped, with the nose of curve at approximately $650^{\circ} \mathrm{C}$ and the critical temperature range is from $600^{\circ} \mathrm{C}$ to $750^{\circ} \mathrm{C}$ at $0.1 \mathrm{sec}$ and it implies that the remainder of the austenite transforms to produce a microstructure composed of $99.5 \%$ martensite and $0.5 \%$ non-martensite transformation. TTP diagram also indicates that low cooling rate leads to the poor mechanical properties due to the increase of critical time with an amount of new phase to reduce the properties.

\section{FE-simulation Coupled with QFA}

FE model and conditions for U-channel part. FE-simulation in this study is employed to obtain the temperature curves of blank during partial quenching of which results are coupled with QFA to calculate the hardness of partial quenched part. In this study, the FE-simulation is conducted using commercial FE code, JSTAMP/NV 2.5.5, with a full model of U-channel part as shown in Fig. 2. The initial blank is a square sheet of $\mathrm{L} 320 \mathrm{~mm} \times \mathrm{W} 320 \mathrm{~mm}$ with the thicknesses of $1.0 \mathrm{~mm}$ and heating temperatures of tools are from $350^{\circ} \mathrm{C}$ to $450^{\circ} \mathrm{C}$ to evaluate the effect of temperature on the hardness of partially quenched part. Also, the material model used in FE-simulation is the Cowper-Symonds model which is an elastic visco-plastic model with thermal effect [13]. The conditions of FE-simulation for hot stamping are summarized in Table 3.

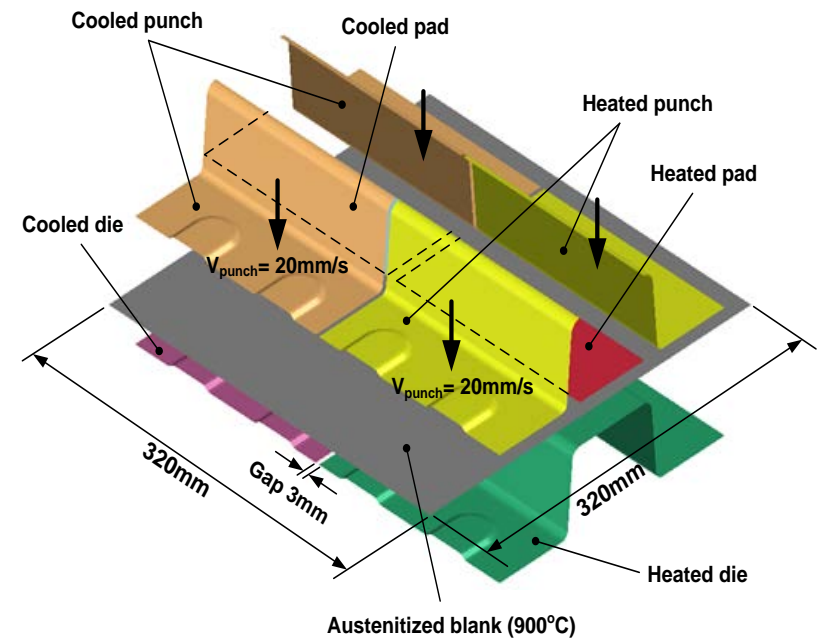

Figure 2. FE model of U-channel part for partial quenching analysis.

FE-simulation of partial quenching is performed for entire stages such as blank heating, transferring, forming and quenching process which is equal with the conventional hot stamping. The blanks were heated from room temperature $\left(20^{\circ} \mathrm{C}\right)$ to $900^{\circ} \mathrm{C}$ for $5 \mathrm{~min}$ for the austenitizing condition in which convective heat transfer coefficient $\left(h_{\text {conv }}\right)$ is inputted as value of $20 \mathrm{~W} / \mathrm{m}^{2} \cdot \mathrm{K}$ throughout the surface of blank. And then, heated blank was transferred to the tools 
for $7 \mathrm{sec}$, in the forming stage, punch and holder move down to the die together with velocity of $20 \mathrm{~mm} / \mathrm{s}$. Finally, in the quenching stage, all tools keep the position at final forming stage for 14 sec. This stage is very important to predict hardness of blank which is directly affected by the interface heat transfer coefficient $\left(h_{\text {inter }}\right)$ between the blank and tools. Hence, this study used the experimentally measured interface heat transfer coefficients considering contact pressure from $0 \mathrm{MPa}$ to $40 \mathrm{MPa}$.

Table 3. The conditions of FE-simulation for partial quenching.

\begin{tabular}{|c|c|c|}
\hline \multicolumn{2}{|c|}{ Conditions } & Values \\
\hline \multicolumn{2}{|c|}{ Young's modulus (GPa) } & 100 \\
\hline \multicolumn{2}{|c|}{ Poisson's ratio } & 0.3 \\
\hline \multicolumn{2}{|c|}{ Thermal expansion $(1 / \mathrm{K})$} & $1.44 \mathrm{e}-05$ \\
\hline \multicolumn{2}{|c|}{ Heat conductivity of tools $(\mathrm{W} / \mathrm{m} \cdot \mathrm{K})$} & 32 \\
\hline \multicolumn{2}{|c|}{ Friction coefficient $(\mu)$} & 0.4 \\
\hline \multicolumn{2}{|c|}{ Material model } & Cowper-Symonds [13] \\
\hline \multicolumn{2}{|c|}{$\begin{array}{l}\text { Convective heat transfer coefficient; } h_{\text {conv }} \\
\qquad\left(\mathrm{W} / \mathrm{m}^{2} \cdot \mathrm{K}\right)\end{array}$} & 20 \\
\hline \multicolumn{2}{|c|}{$\begin{array}{l}\text { Interface heat transfer coefficient; } h_{\text {inter }} \\
\left(\mathrm{W} / \mathrm{m}^{2} \cdot \mathrm{K}\right)\end{array}$} & As function of pressure \\
\hline \multicolumn{2}{|c|}{ Punch speed $(\mathrm{mm} / \mathrm{s})$} & 20 \\
\hline \multicolumn{2}{|c|}{ Holder force $(\mathrm{kN})$} & 14.4 \\
\hline \multirow{3}{*}{$\begin{array}{l}\text { Temperature } \\
\left({ }^{\circ} \mathrm{C}\right)\end{array}$} & Blank & 900 \\
\hline & Cooled tools & 20 \\
\hline & Heated tools & $350,400,420,450$ \\
\hline
\end{tabular}

The temperatures of the blank predicted by FE-simulation were used in the QFA to calculate the hardness. The temperatures were extracted for each stage of partial quenching according to the time step $(\Delta t)$ of Eq. (3). And then, the extracted temperatures were inputted to the programmed QFA by MATLAB 2010a, in which data were calculated for the Vickers hardness values of all elements of the U-channel part. Finally, post processing of the calculated hardness was conducted using the user-subroutine based on LS-Dyna, which could visibly show the hardness distribution of the hot stamped hat shape.

Analytical results of hardness distribution for partial quenching. It is generally known that high cooling rate during quenching enhances hardenability and mechanical properties of boron steel with a formation of martensitic and bainatic microstructure [14]. Fig. 3 illustrates the hardness distributions of partially quenched U-channel part according to heating temperature of tools. In the results, predicted hardness distributions at cooled region were equal in all conditions from 454.1 Hv to 454.4 Hv. However, in case of heated region, as increasing the tool temperature, hardness of partially quenched part decreases due to a drop of cooling rate for austenitized blank with high temperature. Especially, hardness distribution of heating temperature of $450^{\circ} \mathrm{C}$ was maximally declined with a value of $278.8 \mathrm{Hv}$ as shown in Fig. 3(d).

It can be also found that hardnesses at top of part was mostly higher than other regions because this region was firstly pressed and quenched by pad with a high cooling rate. On the contrary, hardness of wall was low in comparison to other region due to insufficient contact pressure between tools and blank. Maximum difference between wall and top at cooled region was $35 \mathrm{Hv}$ and that of heated region was from $10 \mathrm{Hv}$, respectively. Thus, this study can predict the hardness distribution of partially quenched U-channel part using the FE-simulation coupled with QFA.

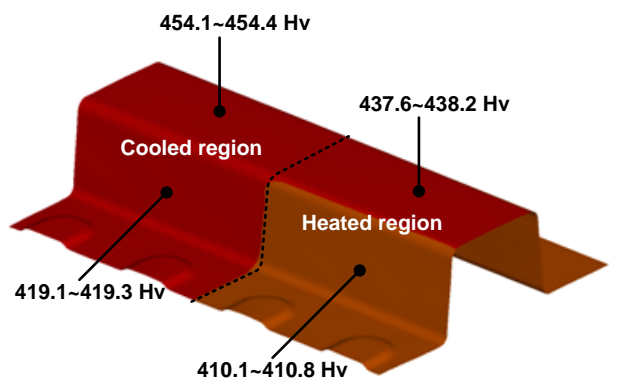

(a) Tool temp. $25^{\circ} \mathrm{C} \& 350^{\circ} \mathrm{C}$

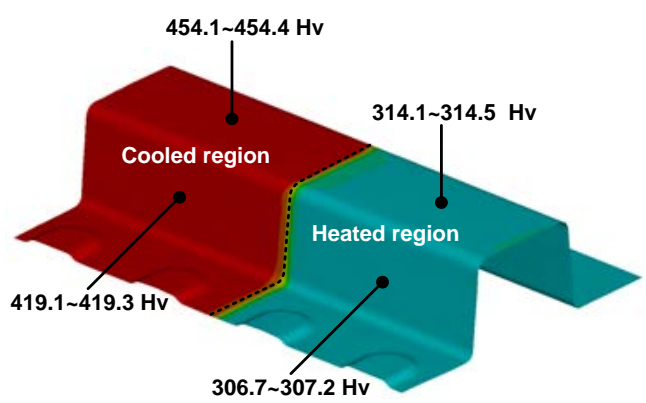

(c) Tool temp. $25^{\circ} \mathrm{C} \& 420^{\circ} \mathrm{C}$

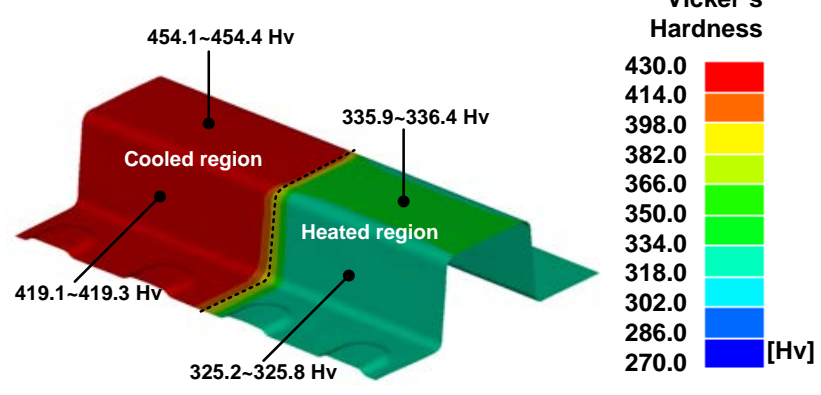

(b) Tool temp. $25^{\circ} \mathrm{C} \& 400^{\circ} \mathrm{C}$

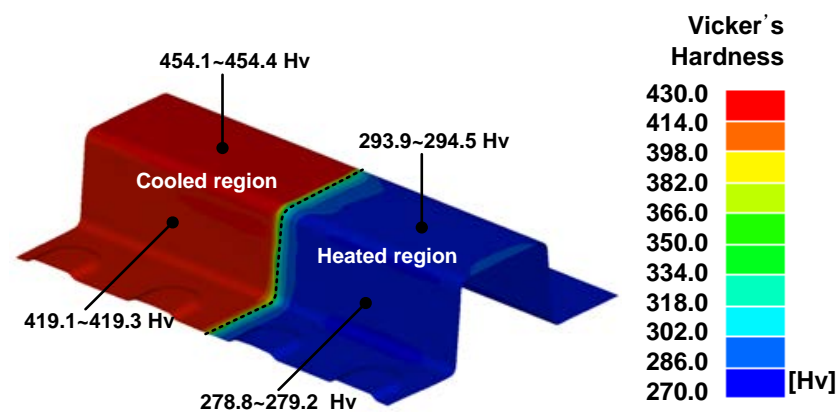

(d) Tool temp. $25^{\circ} \mathrm{C} \& 450^{\circ} \mathrm{C}$

Figure 3. Distributions of hardness according to tool temperatures (Cooling temp. \& Heating temp.) 


\section{Experiment of Partial Quenching}

Experimental procedure. Experiment of partial quenching was performed to prove the reliability of the predicted results by FE-simulation coupled with QFA. Fig. 4 shows the experimental set-up of partial quenching for U-channel part. Tools were composed of punch, pad and die of which material was made of AISI-H13 steel. In order to obtain the tailored property of part, in the heated region, tools were heated by cartridge heaters of total 30ea according to heating temperatures from $350^{\circ} \mathrm{C}$ to $450^{\circ} \mathrm{C}$ as shown in Fig. 4(b). In the opposite region (cooled tools), cooling channels of total 32ea were used to rapid cooling of blank to gain the high strength property. In addition, air gap of 3mm was implemented between heated and cooled tools for the adequate insulation.

Holder force of $14.4 \mathrm{kN}$ was applied by a four gas springs with the single action hydraulic press of 50 ton capacity. Punch speed was fixed to $20 \mathrm{~mm} / \mathrm{s}$ with total distance of $80 \mathrm{~mm}$ which included both moving and forming strokes of $20 \mathrm{~mm}$ and $60 \mathrm{~mm}$, respectively. Four guide posts were employed to prevent the mismatching center between punch and die. Lifter pin sets were also used to precise array between austenitized blank and die before forming stage.

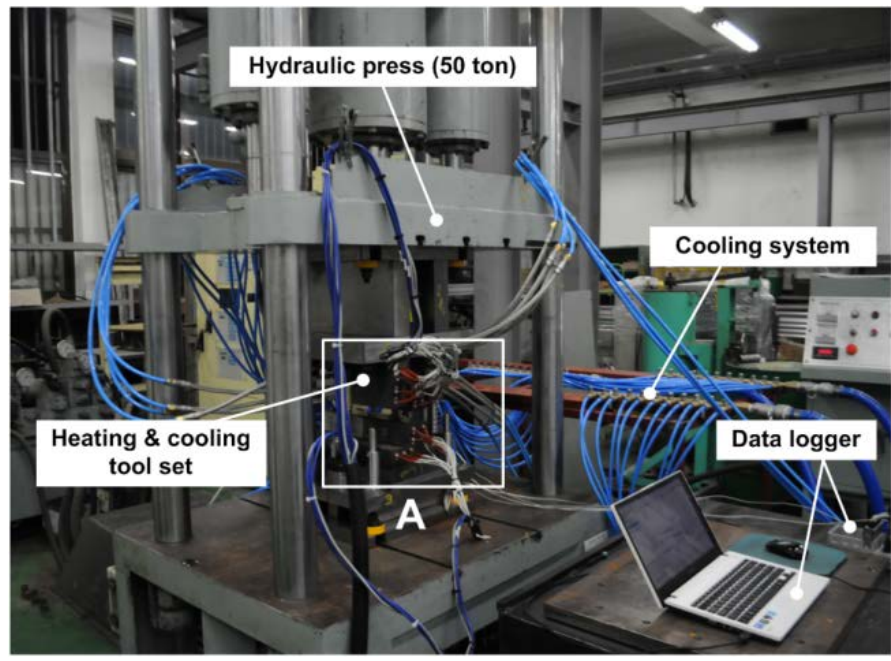

(a) Overall view

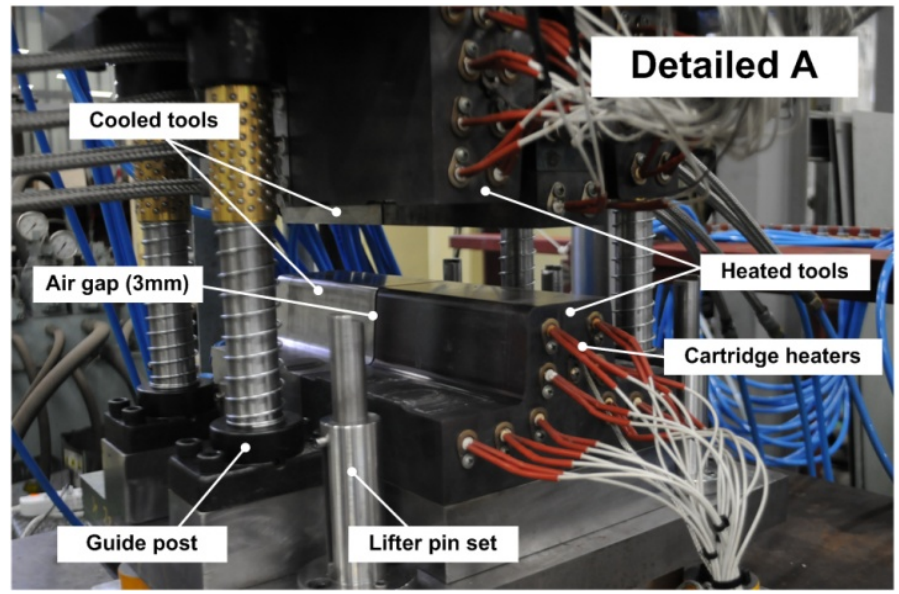

(b) Detailed A

Figure 4. Experimental set-up for partial quenching of U-channel part

The blanks were austenitized at $900^{\circ} \mathrm{C}$ for $5 \mathrm{~min}$ in the electric furnace and they were manually transferred to the die. Blank temperatures were measured through the K-type thermocouples of $\varnothing 0.5 \mathrm{~mm}$ in diameter considering the blank thickness of $1.0 \mathrm{~mm}$. In addition, cooling curve for each stage during partial quenching was representatively evaluated at the top of part according to heating temperature of tool. This study adopted the Vickers hardness to evaluate the mechanical property of partially quenched part. The hardnesses were measured at predefined points of heated and cooled regions, respectively, and hardness profiles were elvaluated at the transition region of nearby air gap. Also, section of partially quenched part was polished before measurement of hardness and an average value of five measurements was used for each points.

Validation of predicted results. Fig. 5 shows the 
partially quenched U-channel parts by tool tempering and measurement points of formed part for hardness and temperature. Also, experimentally measured and predicted temperature histories of blank at predefined locations of P1 points were depicted in Fig. 6(a) according to tool temperatures. The temperature histories from the FE-simulation are very similar to those of experimentally measured ones at each stage such as transferring, forming and quenching. Predicted hardnesses of hot partially quenched part by FE-simulation coupled with QFA are compared with the measured ones as shown in Fig. 6(b). Experimental and analytical results indicate that hardness profile does not affected by tool temperature of $350^{\circ} \mathrm{C}$ because blank temperature at this condition is cooled down below start of martensite temperature. However, tool temperatures above $400^{\circ} \mathrm{C}$ lead to the dramatic drop of hardnesses in which hardness decrease with the increase of tool temperature. The agreement between experiment and analytical hardnesses of partially quenched part is in general satisfactory with average percentage of deviation of $7.4 \%$. Therefore, FE-simulation coupled with QFA suggested in this study is very useful method to predict the hardness of partially quenched part.

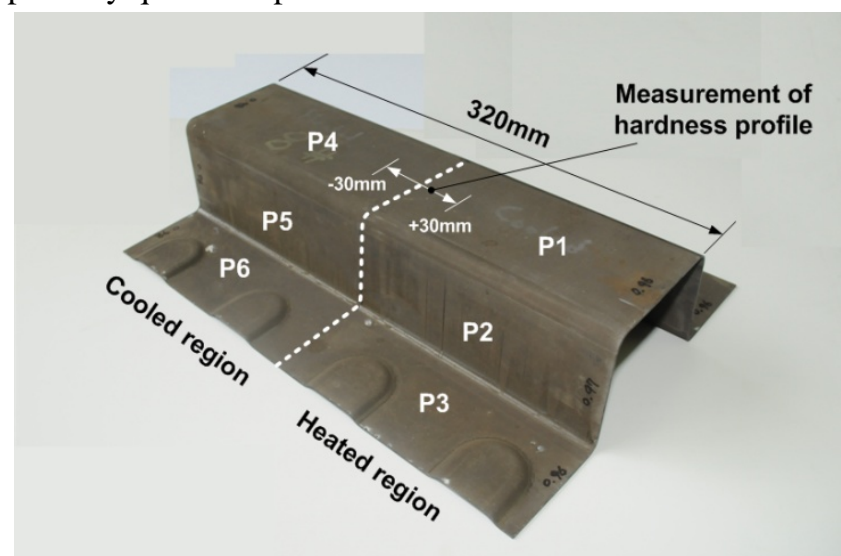

Figure 5. Measurement points of hardness and temperature for partially quenched part

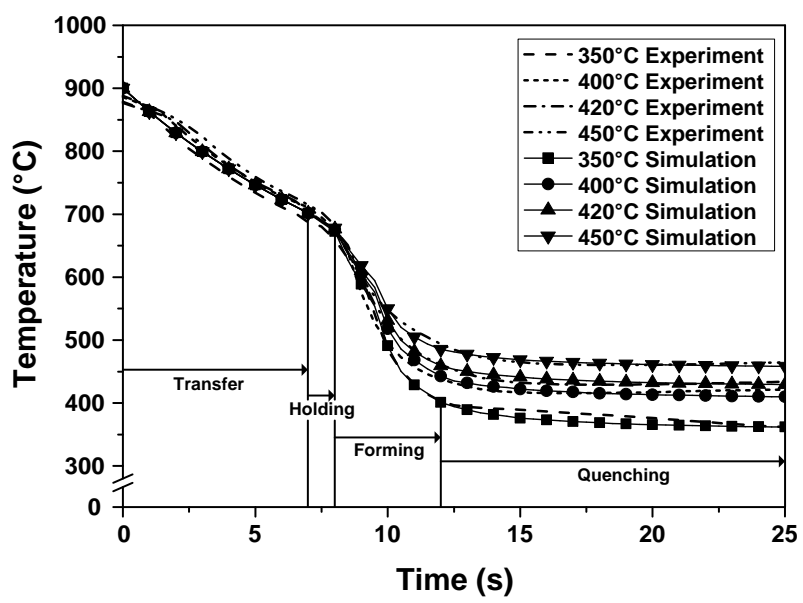

(a) Temperature history

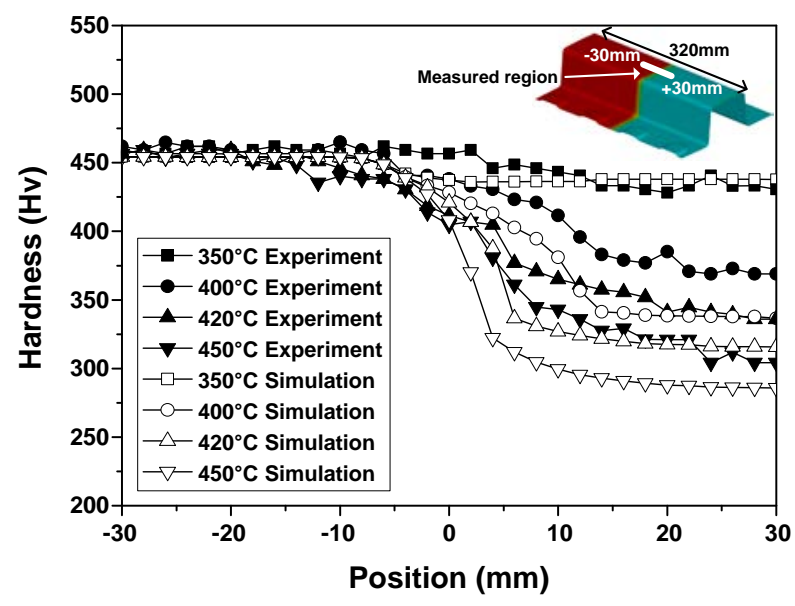

(b) Hardness profile

Figure 6. Comparison between predicted and measured results for partially quenched part.

\section{Conclusions}

In this study, hardness distribution of partially quenched U-channel parts by tool heating was predicted by the FE-simulation coupled with QFA. Based on the analysis and experiment, the following conclusion can be drawn:

1) Dilatometry test was performed to obtain the cooling curves according to various cooling rates which were used to determine the material constants of QFA and it also shows the TTP diagram of boron steel at austenitizing condition of $900^{\circ} \mathrm{C}$ for $5 \mathrm{~min}$.

2) FE-simulation coupled with QFA was conducted to predict the cooling curves and hardness distribution of partially quenched part. This result indicates that increase of tool temperature brought out the dramatic reduction of hardness of which heating temperature at $450^{\circ} \mathrm{C}$ was maximally declined with a value of $280 \mathrm{Hv}$

3) The validation of FE-simulation coupled with QFA was conducted by comparing the experimental results with regard to the measured Vicker's hardness profile between heated and cooled region and the predicted hardnesses of parts were in good agreement with the measured ones within a maximum error of $7.4 \%$.

4) Mechanical properties in the partial quenching can be easily and precisely predicted by the FE-simulation coupled with QFA. This method can be also used to design the process conditions for acquirement of desired mechanical properties.

\section{Acknowledgements}

This work was supported by the National Research Foundation of Korea (NRF) grant funded by the Korea government (MSIP) (No. 2012R1A5A1048294). 


\section{REFERENCES}

[1] J. Min, J. Lin, Y. Min and F. Li: Mater. Sci. Eng., Vol. 550 (2012), pp. 375-387

[2] B. T. Tang, S. Bruschi, A. Ghiotti and P. F. Bariani: Finite. Elem. Anal. Des., Vol. 81 (2014), pp. 69-81

[3] R. George, A. Bardelcik and M. J. Worswick: J. Mater. Process. Technol., Vol. 212 (2012), pp. 2386-2399

[4] H. Hagenah, M. Merklein, M. Lechner, A. Schaub and S. Lutz: $9^{\text {th }}$ CIRP Conf. Intell. Comput. Manuf. Eng., (2015), 167-172

[5] M. Merklein, M. Wieland, M. Lechner, S. Bruschi and A. Ghiotti: J. Mater. Process. Technol., Vol. 228 (2016), pp. $11 \sim 24$

[6] S. Ertürk, M. Sester, M. Selig, P. Feuser and K. Roll: AIP Conf. Proc., (2011), pp. 610-617
[7] J. S. Kirkaldy and D. Venugopalan: Inter. Conf. Phase Trans. Ferr. Alloys, (1983), pp. 125-148

[8] P. Åkerström P. and M. Oldenburg: J. Mater. Process. Technol., Vol. 174 (2006), pp. 399-406

[9] M. Kianezhad and S. A. Sajjadi: Metall. Mater. Trans. A, Vol. 44A (2013), pp. 2053-2059

[10] J. W. Evancho and J. T. Staley: Metall. Trans., Vol. 5 (1974), pp. 43-47

[11] D. M. Himmelblau: Applied Nonlinear Programmig, McGaw-Hill (1972), pp. 148-157

[12] A. Z. Yazdi, S. A. Sajjadi, S. M. Zebarjad and S. M. Nezhad: J. Mater. Process. Technol., Vol. 199 (2008), pp. 124-129

[13] B. Shapiro: Using LS-Dyna for Hot Stamping, $7^{\text {th }}$ European LS-Dyna Conference (2009)

[14] M. Nikravesh, M. Naderi, G. H. Akbari and W. Bleck: Mater. Des., Vol. 84 (2015), pp. 18 24 